\title{
ANALISA PERENCANAAN SISTEM DRAINASE DALAM UPAYA PENANGGULANGAN BANJIR DI KECAMATAN GANDUSARI KABUPATEN TRENGGALEK
}

\author{
${ }^{1 *}$ Rizqi Dwi Prasetyo, ${ }^{2}$ Yosef Cahyo, ${ }^{3}$ Ahmad Ridwan, \\ Fakultas Teknik, Universitas Kadiri. \\ e-mail: ${ }^{{ }^{*}}$ rizqidwiprasetyo@gmail.com, ${ }^{2}$ yosef.cs@unik-kediri.ac.id, ${ }^{3}$ ahmad ridwan@unik- \\ kediri.ac.id.
}

\begin{abstract}
In industrial areas or densely populated settlements, generally found channels that function besides to drain rainwater as well as to discharge domestic wastewater or dirty water from households. Drainage systems are often the main problem in the occurrence of flooding. It is necessary to analyze how their performance and resistance to flooding in the District of Gandusari, Trenggalek Regency. For analysis of drainage system planning in flood prevention efforts, the authors used the Van-Breun and Mononobe calculation methods to determine the number of incoming water discharge, the ideal dimension of the channel to accommodate the inlet discharge channel, and calculate the cost budget plan (RAB) of the builder. From the analysis, results obtained a cumulative discharge of rainwater, and dirty water entering the drainage amounted to $0.4695 \mathrm{~m} 3 / \mathrm{sec}$. From the calculation, the ideal dimensions of the drainage can be obtained to be able to accommodate rainwater runoff and dirty water discharge using square channels, where the $1.5 \mathrm{~m}$ channel height is all added to the water level of $0.2 \mathrm{~m}$ and $0.7 \mathrm{~m}$ in width $500 \mathrm{~m}$. While the budget plan for the construction costs is Rp. 794,048,000.00 -
\end{abstract}

Keywords : Flood, Drainage, Mitigation, Water Discharge

\begin{abstract}
ABSTRAK
Di daerah industri atau pemukiman padat penduduk umumnya ditemukan saluran yang berfungsi selain untuk mengalirkan air hujan juga sekaligus untuk pembuangan air limbah domestik ataupun air kotor dari rumah tangga. System drainase sering menjadi pokok masalah dalam terjadinya banjir, maka perlu di Analisa bagaimana kinerjanya dan ketahanan terhadap banjir di Kecamatan Gandusari Kabupaten Trenggalek. Untuk analisis perencanaan sistem drainase dalam upaya penanggulangan banjir penulis menggunakan metode perhitungan Van-Breun dan Mononobe untuk mengetahui angka debit air yang masuk, dimensi ideal saluran untuk menampung saluran debit air masuk dan menghitung rencana anggaran biaya (RAB) pembangunanya. Dari hasil analisa didapatkan debit komulatif air hujan dan air kotor yang masuk ke drainase sebesar $0.4695 \mathrm{~m}^{3} /$ detik. Dari perhitungan didapatkan dimensi saluran drainase yang ideal agar mampu menampung limpasan air hujan dan debit air kotor dengan menggunakan saluran berbentuk persegi, dimana tinggi saluran $1,5 \mathrm{~m}$ semuanya ditambahkan dengan tinggi jagaan air sebesar 0,2 m dan lebar 0,7 m dengan panjang $500 \mathrm{~m}$. Sedangkan rencana Anggaran Biaya pembangunannya sebesar Rp. 794.048.000,00,-
\end{abstract}

Kata Kunci : Banjir, Drainase, Penanggulangan, Debit Air 


\section{PENDAHULUAN}

Masyarakat akan selalu tertarik untuk berkumpul atau menghuni suatu wilayah, dimana pada area tersebut terdapat banyak fasilitas untuk memenuhi kebutuhan mereka. Wilayah tersebut biasanya adalah kawasan industri dan perdagangan. Secara teknis pembangunan hunian dan sarana pada daerah tersebut berkembang searah mengikuti laju peningkatan jumlah penduduk dan fasilitas industri, [1][2][3]. Namun faktanya fasilitas lingkungan seperti drainase dan pengelolaan limbah domestik belum terlalu diperhatikan, Sehingga menjadi masalah lungkungan [4]. Permasalahan drainase sangat komplek kerena menyangkut bukan hanya lingkunan fisik saja melaikan terkait dengan masalah lingkungan social budaya serta karakteristik daerah, [5][6][7]. Di daerah industri atau pemukiman padat penduduk umumnya ditemukan saluran yang berfungsi selain untuk mengalirkan air hujan juga sekaligus untuk pembuangan air limbah domestik ataupun air kotor dari rumah tangga, [8]. Hal ini tentu akan mempengaruhi orientasi perencanaan serta kriteria sistem drainase yang akan dibuat. Fakta dan masalah diatas salah satunya terjadi di Kecamatan Gandusari, Kabupaten Trenggalek. Di daerah tersebut terdapat banyak industri genteng dan persebaran penduduk yang cukup padat, dimana setiap musim penghujan selalu terjadi banjir. Melihat kondisi tersebut, maka perlu dilakukan perencanaan sistem drainase dalam upaya penanggulangan banjir, [9][10][11].

\section{METODE PERENCANAAN}

\subsection{Metode perencanaan}

Metode perencanaan adalah cara - cara yang ditempuh untuk merumuskan sebuah perencanaan dengan mengacu pada hasil observasi, literatur, dan data statistik yang diperoleh, [12][13]. Garis besar metode perencanaan analisa perencanaan sistem drainase dalam upaya penanggulangan banjir di kecamatan gandusari kabupaten trenggalek adalah sebagai berikut, [14][15]:

Uraian Bagian:

A. Persiapan

Pekerjaan persiapan meliputi observasi awal di wilayah yang akan direncanakan, sebagai acuan penentuan titik yang akan menjadi sampel perhitungan.

\section{B. Pengumpulan Data}

Sebagai dasar perencanaan perlu adanya data dokumentasi, standar analisa dari dinas pekerjaan umum dan pengumpulan data literature, [16].

C. Studi Literatur 
Agar kegiatan ini menjadi efektif, maka studi literature mutlak diperlukan. Hal ini berkaitan dengan penentuan metode perhitungan yang akan dipakai sebagai dasar perhitungan, [17].

D. Olah Data/ Perencanaan

Data yang sudah terkumpul akan digunakan untuk menganalisa beberapa aspek perencanaan yang meliputi:

1. Analisa Data Curah Hujan, [18][19].

a) Data curah hujan tahunan.

b) Perhitungan curah hujan daerah.

c) Perhitungan curah hujan rancangan.

d) Perhitungan intensitas curah hujan.

e) Perhitungan debit air hujan.

2. Perhitungan Debit Air Kotor

3. Perhitungan Dimensi Saluran.

4. Perhitungan Rencana Anggaran Biaya

E. Hasil Perencanaan

Akhir dari kegiatan ini adalah menghasilkan data analisa perencanaan sistem drainase dalam upaya penanggulangan banjir di kecamatan Gandusari, kabupaten Trenggalek, [20][21].

\subsection{Langkah kerja dan alur pembahasan}

Untuk mewujudkan hasil perencanaan saluran drainase di Kecamatan Gandusari yang sering terjadi banjir, dapat dilakukan tahapan perencanaan sebagai berikut, [22][23]:

A. Pengumpulan Data

1) Peta data topografi

2) Data curah hujan yang diambil dari stasiun Mnjungan, Kampak dan Gandusari.

B. Pengolahan Data

1) Menghitung curah hujan maksimum daerah.

2) Menghitung curah hujan rancangan.

3) Menghitung intensitas curah hujan, [24].

C. Perhitungan Debit Banjir Rancangan, [25][26].

1) Menghitung debit air kotor.

2) Menghitung debit air hujan.

D. Perhitungan dimensi saluran berdasarkan debit banjir rancangan, [27].

E. Perhitungan Rencana Anggaran Biaya

\section{PEMBAHASAN}




\subsection{Perhitungan Curah Hujan Daerah}

Perhitungan curah hujan daerah dilakukan dengan metode tinggi rata-rata.

$d=\frac{d_{1}+d_{2}+d_{3}+\ldots d_{n}}{n}=\sum_{i}^{n} \frac{d i}{n}$

Contoh perhitungan:

Data hujan pada tahun 1992

Stasiun Pacitan $\left(\mathrm{d}_{1}\right)$

$=116 \mathrm{~mm}$

Stasiun Nawangan $\left(\mathrm{d}_{2}\right)$

$=114 \mathrm{~mm}$

Stasiun Ketro $\left(\mathrm{d}_{3}\right)$

$=118 \mathrm{~mm}$

$d=\frac{d_{1}+d_{2}+}{n}$

$d=\frac{116+114+118}{3}=116 \mathrm{~mm}$

Tabel 1. Data Curah Hujan Maksimal pada Sta. Gandusari, Kampak dan Munjungan.

\begin{tabular}{|c|c|c|c|c|c|}
\hline No. & Tahun & Sta. Gandusar & Sta. Kampak & Sta. Munjungan & Hujan max. daerah \\
\hline 1 & 1998 & 140 & 105 & 99 & 114.66 \\
\hline 2 & 1999 & 88 & 115 & 97 & 100 \\
\hline 3 & 2000 & 124 & 137 & 137 & 132.66 \\
\hline 4 & 2001 & 103 & 71 & 155 & 109.66 \\
\hline 5 & 2002 & 86 & 145 & 93 & 108 \\
\hline 6 & 2003 & 117 & 101 & 169 & 129 \\
\hline 7 & 2004 & 167 & 199 & 273 & 213 \\
\hline 8 & 2005 & 65 & 88 & 359 & 170.66 \\
\hline 9 & 2006 & 83 & 43 & 126 & 84 \\
\hline 10 & 2007 & 115 & 129 & 163 & 135.66 \\
\hline 11 & 2008 & 80 & 56 & 97 & 97.66 \\
\hline 12 & 2009 & 58 & 66 & 157 & 123.66 \\
\hline 13 & 2010 & 94 & 54 & 223 & 172.66 \\
\hline 14 & 2011 & 72 & 75 & 371 & 103.66 \\
\hline 15 & 2012 & 60 & 92 & 159 & 156 \\
\hline 16 & 2013 & 81 & 101 & 286 & 127.33 \\
\hline 17 & 2014 & 77 & 142 & 163 & 114 \\
\hline 18 & 2015 & 125 & 112 & 105 & 87.66 \\
\hline 19 & 2016 & 147 & 155 & 172 & \\
\hline 20 & 2017 & 88 & 92 & 83 & \\
\hline
\end{tabular}

Sumber: Pengolahan Data

Setelah didapat data curah hujan daerah, kemudian data tersebut diurutkan dari nilai yang terbesar hingga nilai yang terkecil. Untuk selanjutnya digunakan dalam perhitungan Curah Hujan Rancangan dengan metode Gumbel. 


\subsection{Perhitungan Curah Hujan Rancangan}

Metode Gumbel

$X=\bar{X}+\frac{Y t-Y n}{S n} S d$

Keterangan:

$\bar{X} \quad=$ curah hujan rata-rata.

Yt $=$ simpangan tereduksi kala ulang

$=-\operatorname{In}\left|-\operatorname{In} \frac{T R-1}{T R}\right|$ dengan TR = kala ulang

Yn $\quad=$ simpangan rata-rata tereduksi

$\mathrm{Sn} \quad=$ simpangan baku tereduksi

$\mathrm{Sd} \quad=$ simpangan baku

$\mathrm{Sd} \quad=\sqrt{\frac{\sum|X i-\bar{X}|^{2}}{n-1}}$

Tabel 2. Perhitungan Curah Hujan Rancangan Metode Gumbel

\begin{tabular}{|c|c|c|c|c|c|}
\hline No. & $X(\mathrm{~mm})$ & $\mathrm{P}(\%)$ & TR & X-X rata-rata & $(\mathrm{X}-\mathrm{X} \text { rata-rata })^{2}$ \\
\hline 1 & 213.00 & 4.76 & 21.00 & 87.42 & 7641.674 \\
\hline 2 & 172.67 & 9.52 & 10.50 & 47.08 & 2216.840 \\
\hline 3 & 170.67 & 14.29 & 7.00 & 45.08 & 2032.507 \\
\hline 4 & 158.00 & 19.05 & 5.25 & 32.42 & 1050.840 \\
\hline 5 & 156.00 & 23.81 & 4.20 & 30.42 & 925.174 \\
\hline 6 & 135.67 & 28.57 & 3.50 & 10.08 & 101.674 \\
\hline 7 & 132.67 & 33.33 & 3.00 & 7.08 & 50.174 \\
\hline 8 & 129.00 & 38.10 & 2.63 & 3.42 & 11.674 \\
\hline 9 & 127.33 & 42.86 & 2.33 & 1.75 & 3.063 \\
\hline 10 & 123.67 & 47.62 & 2.10 & -1.92 & 3.674 \\
\hline 11 & 114.67 & 52.38 & 1.91 & -10.92 & 119.174 \\
\hline 12 & 114.00 & 57.14 & 1.75 & -11.58 & 134.174 \\
\hline 13 & 109.67 & 61.90 & 1.62 & -15.92 & 253.340 \\
\hline 14 & 108.00 & 66.67 & 1.50 & -17.58 & 309.174 \\
\hline 15 & 103.67 & 71.43 & 1.40 & -21.92 & 480.340 \\
\hline 16 & 100 & 76.190 & 1.31 & -25.58 & 654.507 \\
\hline 17 & 93.67 & 80.952 & 1.24 & -31.92 & 1018.674 \\
\hline 18 & 87.67 & 85.714 & 1.17 & -37.92 & 1437.674 \\
\hline 19 & 84.00 & 90.476 & 1.11 & -41.58 & 1729.174 \\
\hline 20 & 77.67 & 95.238 & 1.05 & -47.92 & 2296.007 \\
\hline Jumlah & 2511.67 & & & Jumlah & 22469.528 \\
\hline Rata-rata & 125.58 & & & $\mathrm{~S}$ & 17.75 \\
\hline Yn & 0.5236 & & & & \\
\hline Sn & 1.0628 & & & & \\
\hline
\end{tabular}

Sumber: Pengolahan data

\subsection{Perhitungan Intensitas Curah Hujan}

Karena data yang ada adalah curah hujan harian, maka intensitas curah hujan dapat dihitung dengan rumus Van-Breun dan Mononobe. Curah hujan $\left(\mathrm{R}_{24}\right)=128.79 \mathrm{~mm}$. 
1. Metode Mononobe

$I=\left(\frac{R_{24}}{24}\right)\left(\frac{24}{t}\right)^{2 / 3}$

Keterangan :

I $\quad=$ intensitas hujan $(\mathrm{mm} / \mathrm{jam})$

$\mathrm{R}=$ curah hujan harian selama $24 \mathrm{jam}(\mathrm{mm})$

$\mathrm{t} \quad=$ lamanya hujan (jam)

Tabel 3. Perhitungan Intensitas Metode Mononobe

\begin{tabular}{|c|c|c|c|}
\hline menit & Jam & $\mathrm{R}_{24}$ & $\mathrm{I}(\mathrm{mm} / \mathrm{jam})$ \\
\hline 5 & 0.08 & \multirow{25}{*}{128.79} & 240.48017 \\
\hline 15 & 0.25 & & 112.50692 \\
\hline 30 & 0.50 & & 70.87492 \\
\hline 45 & 0.75 & & 54.08769 \\
\hline 60 & 1.00 & & 44.64840 \\
\hline 75 & 1.25 & & 38.47683 \\
\hline 90 & 1.50 & & 34.07311 \\
\hline 105 & 1.75 & & 30.74543 \\
\hline 120 & 2.00 & & 28.12673 \\
\hline 135 & 2.25 & & 26.00265 \\
\hline 150 & 2.50 & & 24.23888 \\
\hline 165 & 2.75 & & 22.74665 \\
\hline 180 & 3.00 & & 21.46471 \\
\hline 195 & 3.25 & & 20.34934 \\
\hline 210 & 3.50 & & 19.36841 \\
\hline 225 & 3.75 & & 18.49773 \\
\hline 240 & 4.00 & & 17.71873 \\
\hline 255 & 4.25 & & 17.01688 \\
\hline 270 & 4.50 & & 16.38064 \\
\hline 285 & 4.75 & & 15.80072 \\
\hline 300 & 5.00 & & 15.26954 \\
\hline 315 & 5.25 & & 14.78086 \\
\hline 330 & 5.50 & & 14.32949 \\
\hline 345 & 5.75 & & 13.91107 \\
\hline 360 & 6.00 & & 13.52192 \\
\hline
\end{tabular}

Sumber: Pengolahan Data

Perhitungan untuk $\mathrm{t}=5$ menit

$I=\left|\frac{R_{24}}{24}\right| x\left|\frac{24}{t}\right|^{2 / 3}$

$I=\left|\left(\frac{128.79}{24}\right)\right| x\left|\left(\frac{24}{0.08}\right)\right|^{2 / 3}=240.480 \mathrm{~mm} / \mathrm{jam}$

Dari analisa di atas, maka rumus yang dipakai untuk perhitungan intensitas adalah Mononobe.

$$
I=\left|\frac{R_{24}}{24}\right| x\left|\frac{24}{t}\right|^{2 / 3}=\frac{128.79}{t^{2 / 3}}
$$




\subsection{Perhitungan Debit Air Hujan}

Metode Rasional

$\rightarrow$ Berlaku jika luas DAS < 300 ha

$\mathrm{Q}=\frac{1}{360}$. C . I . A

$\mathrm{Q}=0.002778$. C . I . A

Keterangan :

$\mathrm{Q}=$ debit banjir rancangan $\left(\mathrm{m}^{3} /\right.$ detik$)$

$\mathrm{C}=$ koefisien pengaliran

$\mathrm{I}=$ intensitas hujan pada waktu konsentrasi /c ( $\mathrm{mm} / \mathrm{jam})$

$\mathrm{A}=$ luas daerah pengaliran (ha)

Penentuan waktu konsentrasi menurut Kirpich :

$\mathrm{tc}=\mathrm{t}_{\mathrm{o}}+\mathrm{t}_{\mathrm{d}}$

tc $=$ waktu konsentrasi (menit)

$\mathrm{t}_{\mathrm{o}}=$ waktu yang diperlukan bagi air untuk mengalir di permukaan lahan sampai jalur sungai yang terdekat (menit)

$t_{d}=$ waktu yang diperlukan bagi air untuk mengalir dari ujung hulu sungai ke ujung hilir sungai (menit)

$\mathrm{t}_{\mathrm{o}}=\frac{0.784(1.1-C) L o^{1 / 2}}{S o^{1 / 3}}$

Lo $=$ panjaang limpasan $(\mathrm{m})$

$\mathrm{C}=$ koefisien pengaliran

So $=$ kemiringan daerah limpasan $(\%)$

$\mathrm{t}_{\mathrm{d}}=\frac{L d}{60 V d}$

$\mathrm{Ld}=$ panjang saluran $(\mathrm{m})$

$60=$ angka konversi, 1 menit $=60$ detik

$\mathrm{Vd}=$ kecepatan rata-rata dalam saluran ( $\mathrm{m} /$ detik).

Perhitungan :

- Saluran 1-2

- $\mathrm{PUH}=2$ tahun

- $\operatorname{Ld}$ (panjang saluran) $=500 \mathrm{~m}$

- Lo (panjang limpasan)

- Jalan $=2.5 \mathrm{~m}$ (jarak as jalan ke saluran)

- Blok = $25 \mathrm{~m}$ (panjang bagian belakang rumah ke saluran)

- A (luas)

- Jalan $=2.5 \mathrm{~m} \times 500 \mathrm{~m}=1250 \mathrm{~m}^{2}$. 
- Blok $=25 \mathrm{~m} \times 500 \mathrm{~m}=12500 \mathrm{~m}^{2}$.

- So (kemiringan limpasan)

- Jalan $=2 \%$

- Blok $=0.5 \%$

- C (koefisien limpasan)

- Jalan $=0.7$ (aspal)

- Blok $=0.5$

- Vd (kecepatan aliran rata-rata)

Karena kemiringan rata-rata dasar saluran $=0.301 \rightarrow \mathrm{Vd}=0.4 \mathrm{~m} /$ detik.

- $\mathrm{t}_{\mathrm{o}}$ (waktu limpasan menuju saluran)

$$
\begin{aligned}
& t_{o}=\frac{0.784(1.1-C) L o^{1 / 2}}{S o^{2 / 3}} \\
& t_{o} \text { jalan }=\frac{0.784(1.1-0.5) 2.5^{1 / 2}}{2^{2 / 3}}=0.31 \text { menit }
\end{aligned}
$$

- $t_{o}$ blok $=\frac{0.784(1.1-0.5) 25^{1 / 2}}{0.5^{2 / 3}}=3.73$ menit

- $t_{d}$ (waktu pengaliran pada saluran dari titik satu ke titik lain)

$$
t_{d}=\frac{L d}{60 \cdot V d}
$$

$t_{d}$ Blok dan Jalan $=\frac{500}{60 \times 0.4}=20.83$ menit

- $t_{c}$ (waktu konsentrasi air)

$$
\begin{aligned}
t_{c}=t_{o}+ & t_{d} \\
t_{c} \text { jalan } & =t_{o}+t_{d} \\
& =0.31+20.83 \\
& =21.15 \text { menit } \\
t_{c} \text { blok } & =t_{o}+t_{d} \\
& =3.73+20.83 \\
& =24.57 \text { menit }
\end{aligned}
$$

- I (intensitas)

$$
\begin{aligned}
& I=\frac{128.79}{t^{2 / 3}} \\
& I \text { jalan }=\frac{128.79}{\left(\frac{21.15}{60}\right)^{2 / 3}}=258.124 \mathrm{~mm} / \mathrm{jam} \\
& I \text { blok }=\frac{128.79}{\left(\frac{24.57}{60}\right)^{2 / 3}}=233.566 \mathrm{~mm} / \mathrm{jam}
\end{aligned}
$$


$60=$ konversi satuan $t_{c}$ dari menit ke jam.

- Q (debit air hujan)

$$
\begin{aligned}
& Q=\frac{1}{36 \cdot 10^{6}} \cdot C \cdot I \cdot A \\
& \mathrm{~A}=\mathrm{m}^{2}, \mathrm{I}=\mathrm{mm} / \mathrm{jam} \\
& Q \text { jalan }=Q=\frac{1}{36.10^{6}} \times 0.7 \times 258.24 \times 1250=0.0628 \mathrm{~m}^{3} / \text { detik } \\
& Q \text { blok }=Q=\frac{1}{36.10^{6}} \times 0.5 \times 233.566 \times 12500=0.406 \mathrm{~m}^{3} / \text { detik } \\
& Q_{\text {total }}=Q_{\text {blok }}+Q_{\text {jalan }} \\
& =0.0628+0.406 \\
& =0.468 \mathrm{~m}^{3} / \text { detik }
\end{aligned}
$$

\subsection{Perhitungan Debit Air Kotor}

Jumlah kebutuhan air rata-rata setiap hari 200liter dan waktu penggunaan air setiap hari 10 jam. Dari kebutuhan air tiap hari tersebut diasumsikan besarnya air yang dibuang adalah $80 \%$.

Debit air kotor yang dibuang per orang :

$Q=80 \% x \frac{\text { kebutuhan air rata }- \text { rata perhari }}{\text { waktu penggunaan air }}$

$Q=80 \% \times \frac{200 \text { liter }}{10 \mathrm{jam}}=16$ liter $/ \mathrm{jam}=4.44 .10^{-6} \mathrm{~m}^{3} /$ detik

Perhitungan debit air kotor

1. Saluran 1-2

2. Type rumah $=36 \rightarrow$ jumlah orang $=5$

3. Jumlah rumah $=60$ unit

4. Debit air kotor/ orang $\quad=4.44 \cdot 10^{-6} \mathrm{~m}^{3} /$ detik

5. Debit air kotor / rumah $=4.44 \cdot 10^{-6} \mathrm{~m}^{3} /$ detik $\times 5$

$$
=2.22 \cdot 10^{-5} \mathrm{~m}^{3} / \text { detik }
$$

6. Debit yang masuk saluran $=2.22 \cdot 10^{-5} \mathrm{~m}^{3} /$ detik $\times 60$

$$
=0.001332 \mathrm{~m}^{3} / \mathrm{detik}
$$

Debit kumulatif salauran 1-2

$$
\begin{aligned}
\mathrm{Q}_{\text {kum }} & =\mathrm{Q}_{\text {air hujan }}+\mathrm{Q}_{\text {air kotor }} \\
& =0.468+0.001332 \\
& =0.469 \mathrm{~m}^{3} / \text { detik }
\end{aligned}
$$

\subsection{Rencana Anggaran Biaya}

Rencana Anggaran Biaya (RAB) adalah hasil akhir perhitungan yang terdiri dari volume, harga satuan, dan jumlah harga. 


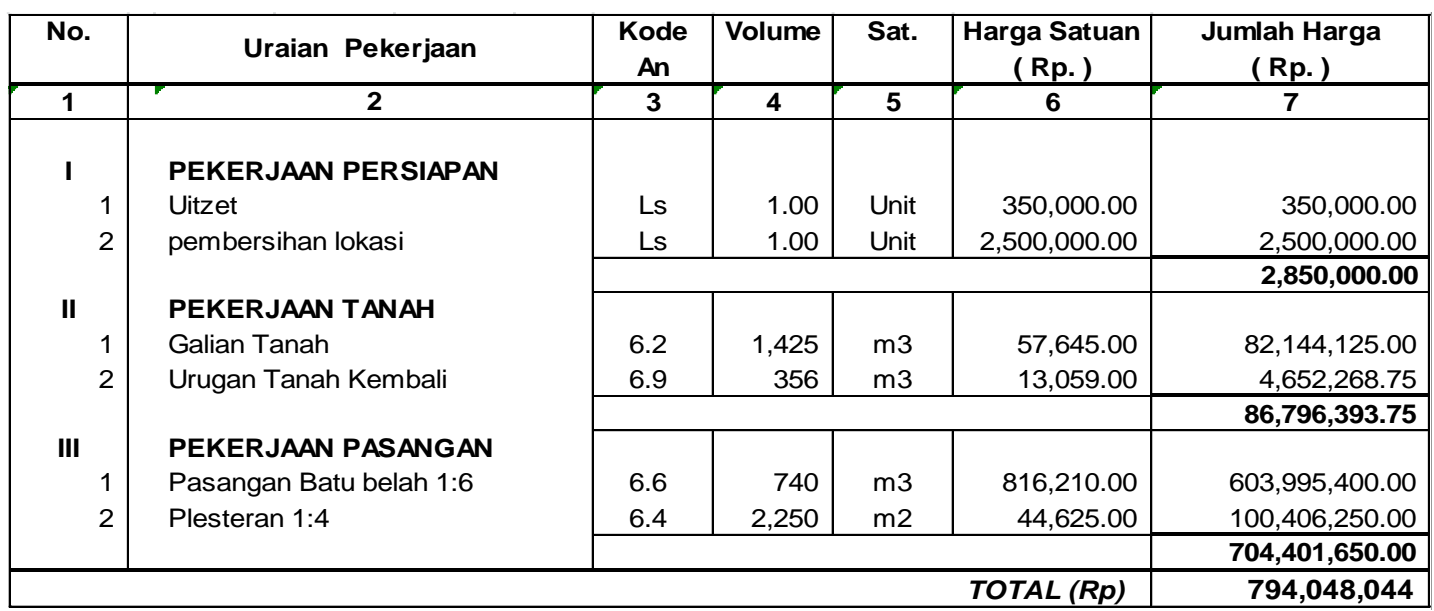

Sumber : hasil perhitungan

Maka pekerjaan saluran drainase tersebut jika dikerjakan pada wilayah kabupaten trenggalek pada tahun 2018, akan menghabiskan dana sebesar Rp. 794.048.000,00,- (Tujuh Ratus Sembilan Puluh Empat Juta Empat Puluh Delapan Ribu Rupiah).

\subsection{Kesimpulan}

\section{KESIMPULAN}

Setelah melalui perhitungan mengenai perencanaan sistem drainase dalam upaya penanggulangan banjir di Kecamatan Gandusari, Kabupaten Trenggalek, dapat disimpulkan bahwa :

a. Debit komulatif air hujan dan air kotor yang masuk ke drainase sebesar 0.4695 $\mathrm{m}^{3} /$ detik;

b. Dari perhitungan didapatkan dimensi saluran drainase yang ideal agar mampu menampung limpasan air hujan dan debit air kotor dengan menggunakan saluran berbentuk persegi, dimana tinggi saluran 1,5 $\mathrm{m}$ semuanya ditambahkan dengan tinggi jagaan air sebesar 0,2 $\mathrm{m}$ dan lebar 0,7 $\mathrm{m}$ dengan panjang $500 \mathrm{~m}$;

c. Rencana Anggaran Biaya pembangunan sebesar Rp. 794.048.000,00,- (Tujuh Ratus Sembilan Puluh Empat Juta Empat Puluh Delapan Ribu Rupiah).

\subsection{Saran}

A. Pengarsipan data curah hujan, data topografi dan dokumentasi bencana sangat diperlukan agar setiap perencanaan selalu mengacu pada data lapangan secara akurat

B. Proses perencanaan drainase seharusnya memperhatikan faktor - faktor yang sangat penting yaitu perhitungan debit dan kemiringan lahan, agar tidak terjadi luapan atau kecepatan aliran yang melebihi ijin

C. Pengerjaan fisik dilapangan harus diawasi secara intensif oleh tim yang kompeten, agar pelaksanaan tidak terjadi kesalahan secara teknis maupun penyimpangan non teknis, sehingga infrastuktur dapat berfungsi secara optimal. 


\section{DAFTAR PUSTAKA}

[1] S. Edisono, I. D. He, Lot, and Kam, "Drainase Perkotaan," Jakarta Gunadarma Press, p. 114, 1997.

[2] B. Triatmodjo, "Hidrologi Terapan," Beta Offset, 2008.

[3] A. I. Candra, S. Anam, Z. B. Mahardana, and A. D. Cahyono, "STUDI KASUS STABILITAS STRUKTUR TANAH LEMPUNG PADA JALAN TOTOK KEROT KEDIRI MENGGUNAKAN LIMBAH KERTAS," Ukarst J. Univ. Kadiri Ris. Tek. Sipil, vol. 2, no. 2, pp. 88-97, 2018.

[4] A. Nashirudin, S. Winarto, and Sudjati, "PERENCANAAN CHECKDAM KALI NGASINAN KANAN DESA NOTOREJO KECAMATAN GONDANG KABUPATEN TULUNGAGUNG," Jurmateks, vol. 1, no. 2, pp. 192-203, 2018.

[5] S. Harto, "Analisis Hidrologi," Yogyakarta: Gramedia Pustaka Utama, 1993, doi: $10.1080 / 02673843.2013 .847850$.

[6] H. . H. Hasmar, Drainasi Terapan. Yogyakarta : UII Press, 2011, 2011.

[7] Suhardjono, "Drainase," Fak. Tek. Univ. Brawijaya, 1984.

[8] H. S. Masduki, "Drainase Permukiman," Inst. Teknol. Bandung, 1990.

[9] S. Kimi, "Analisa Daya Tampung Kolam Retensi Untuk Penanggulangan Banjir Di Daerah Maskarebet Kec. Alang Alang Lebar Palembang," Univ. Muhamadiyah Palembang, vol. 4, 2015.

[10] M. A. Kuncoro, S. Winarto, and Y. C. S. Purnomo, "Studi Penanggulangan Banjir di Kali Batan Kabupaten Kediri,” J. Manaj. Teknol. Tek. Sipil, vol. 1, no. 1, 2018, doi: 10.30737/jurmateks.v1i1.143.

[11] A. A. Saputra, S. Winarto, and A. Ridwan, "PERENCANAAN STRUKTUR BAJA PADA KONSTRUKSI EMPAT LANTAI PADA HOTEL JAYA BAYA,” Jurmateks, vol. 1, no. 2, pp. 248-258, 2018.

[12] A. Prahananto and Sugiyanto, "Perencanaan Drainase Kawasan Puri Anjasmoro Kota Semarang," Univ. Diponegoro Semarang, 2007.

[13] R. Jayadi, "Dasar - Dasar Hidrologi,” 2000.

[14] Kusnaedi, "Sumur Resapan Untuk Pemukiman Perkotaan dan Pedesaan," Jakarta: Penebar Swadaya, 2011.

[15] R. B. Ardian, A. Zakaria, and G. E. Susilo, "Study System Drainase di Fakultas Teknik Universitas Lampung,” J. Rekayasa Sipil dan Desain, vol. 4, no. 3, pp. 503-512, 2016.

[16] I. G. B. S. Suryanti, Irma., Norken, I N., Dharma, "Kinerja Sistem Jaringan Drainase Kota Semarapura Di Kabupaten Klungkung,” J. Spektran, vol. 1, no. 2, pp. 30-38, 2013.

[17] E. Gardjito, A. I. Candra, and Y. Cahyo, "Pengaruh Penambahan Batu Karang Sebagai 
Substitusi Agregat Halus Dalam Pembuatan Paving Block," UKaRsT, vol. 2, no. 1, p. 35, 2018, doi: 10.30737/ukarst.v2i1.374.

[18] A. A. Rofiq, L. D. Krisnawati, and S. Winarto, "KAJIAN KEBUTUHAN AIR BERSIH PDAM NGANCAR KABUPATEN KEDIRI," Jurmateks, vol. 1, no. 1, pp. 126-136, 2018.

[19] S. Sunjoto, "Optimasi Sumur ResapanAir Hujan Sebagai Salah Satu UsahaPencegahan Instrusi Air Laut," Yogyakarta Fak. Tek. Univ. Gadjah Mada, 1988.

[20] C. Soemarto, "Hidrologi Teknik," Usaha Nas. Surabaya, 1986.

[21] Soewarno, "Hidrologi Operasional Jilid Kesatu," Bandung : Citra Aditya Bakti, 2000.

[22] W. T. Cahyono, Y. C. SP, and S. Winarto, "STUDI EFISIENSI PEMBERIAN AIR IRIGASI PADA DESA GROMPOL, KECAMATAN GAMPENGREJO, KABUPATEN KEDIRI," Jurmateks, vol. 1, no. 1, pp. 12-21, 2018.

[23] L. M. Limantara, "Hidrologi Praktis," Bandung : Lubuk Agung, 2010.

[24] Soewarno, "Hidrologi Aplikasi Metode Statistik Untuk Analisa Data," Bandung Nov., 1995.

[25] R. Hepiyanto and H. R. Agusta, "Rancang Bangun Simulasi Distribusi Air Bersih Di Desa Mojosari Kecamatan Mantup," UKaRsT, vol. 2, no. 2, p. 7, 2018, doi: 10.30737/ukarst.v2i2.267.

[26] I. M. Kamiana, Teknik Perhitungan Debit Rencana Bangunan Air, Edisi pert. Yogyakarta : Graha Ilmu, 2016.

[27] R. K. Linsley, M. A. Kohler, and J. L. H. Paulhus, "Hydrology for Engineers," McGrawHill B. Co., 1985. 